\title{
Preoperative endovascular embolization of meningiomas: update on therapeutic options
}

\author{
Aatman Shah, BS, ${ }^{1}$ Omar Choudhri, MD, ${ }^{1,2}$ Henry Jung, MD, ${ }^{1}$ and Gordon Li, MD1 \\ Departments of ${ }^{1}$ Neurosurgery and ${ }^{2}$ Interventional Neuroradiology, Stanford University School of Medicine, Stanford, California
}

In this review paper the authors analyze new therapeutic options for the embolization of meningiomas, as well as the future of meningioma treatment through recent relevant cohorts and articles. They investigate various embolic materials, types of meningiomas amenable to embolization, imaging techniques, and potential imaging biomarkers that could aid in the delivery of embolic materials. They also analyze perfusion status, complications, and new technical aspects of endovascular preoperative embolization of meningiomas. A literature search was performed in PubMed using the terms "meningioma" and "embolization" to investigate recent therapeutic options involving embolization in the treatment of meningioma. The authors looked at various cohorts, complications, materials, and timings of meningioma treatment. Liquid embolic materials are preferable to particle agents because particle embolization carries a higher risk of hemorrhage. Liquid agents maximize the effect of devascularization because of deeper penetration into the trunk and distal tumor vessels. The 3 main imaging techniques, MRI, CT, and angiography, can all be used in a complementary fashion to aid in analyzing and treating meningiomas. Intraarterial perfusion MRI and a new imaging modality for identifying biomarkers, susceptibility-weighted principles of echo shifting with a train of observations (SW-PRESTO), can relay information about perfusion status and degrees of ischemia in embolized meningiomas, and they could be very useful in the realm of therapeutics with embolic material delivery. Direct puncture is yet another therapeutic technique that would allow for more accurate embolization and less blood loss during resection.

http://thejns.org/doi/abs/10.3171/2014.12.FOCUS14728

KEY WORDS embolization; meningioma; therapeutics; biomarkers; Onyx; direct puncture

$\mathrm{M}$ ENINGIOMAS are highly vascularized tumors that arise from the leptomeninges. The term "meningioma" was first coined in 1922 by Harvey Cushing, who published the early works on meningioma surgery. ${ }^{4}$ These tumors most commonly occur extraaxially from arachnoid cell degeneration and dural fibroblasts. Given their origin from arachnoid cap cells, meningiomas occur mainly intradurally (Fig. 1). Virchow first described the classic histological features of the meningioma, known as "psammoma bodies," as a sandlike collection of calcium..$^{24}$ Although generally benign, meningiomas are associated with other sequelae, such as seizures, vision loss, and neurological deficits, based on their location. ${ }^{33}$ Roughly $25 \%-40 \%$ of patients have seizures, and roughly one-third of patients have visual changes. ${ }^{24}$ Treatment involves resection of the meningioma with the accompanying dura and bone, although research is currently being done to develop less invasive and more effective methods of resection to aid in therapeutics. Meningiomas parasitize vascular supply from extracranial and intracranial circulation. Average blood loss during surgery can be anywhere from $200 \mathrm{ml}$ to $2.2 \mathrm{~L}$, and patients may therefore require transfusion. ${ }^{6}$ Blood loss during meningioma resection poses a significant risk and is important in evaluating treatment options. ${ }^{24}$ Preoperative embolization has generally been accepted as an adjuvant therapy reported to make resection easier with few complications. ${ }^{26} \mathrm{~A}$ catheter is guided through the arterial system to the meningioma where an embolic agent is released to reduce blood supply to the tumor. This adjunct therapy was first described by Manelfe et al. in 1973. ${ }^{21}$ Since the inception of catheter embolization, there have been improvements in the catheters and materials used, which have improved therapeutic measures by reducing blood loss, surgical time, and the resulting sequelae. In this paper, we review recent relevant cohorts and analyze new therapeutic options for the embolization of meningiomas by examining embolic materials, imaging techniques, and potential imaging biomarkers that could aid in the delivery of embolic materials. We also analyze perfusion status, types of meningiomas amenable to embolization based on

ABBREVIATIONS ECA = external carotid artery; ICA = internal carotid artery; MMA = middle meningeal artery; NBCA = N-butyl cyanoacrylate; PVA = polyvinyl alcohol; SW-PRESTO = susceptibility-weighted principles of echo shifting with a train of observations.

SUBMITTED October 25, 2014. ACCEPTED December 19, 2014.

INCLUDE WHEN CITING DOI: 10.3171/2014.12.FOCUS14728.

DISCLOSURE The authors report no conflict of interest concerning the materials or methods used in this study or the findings specified in this paper. 


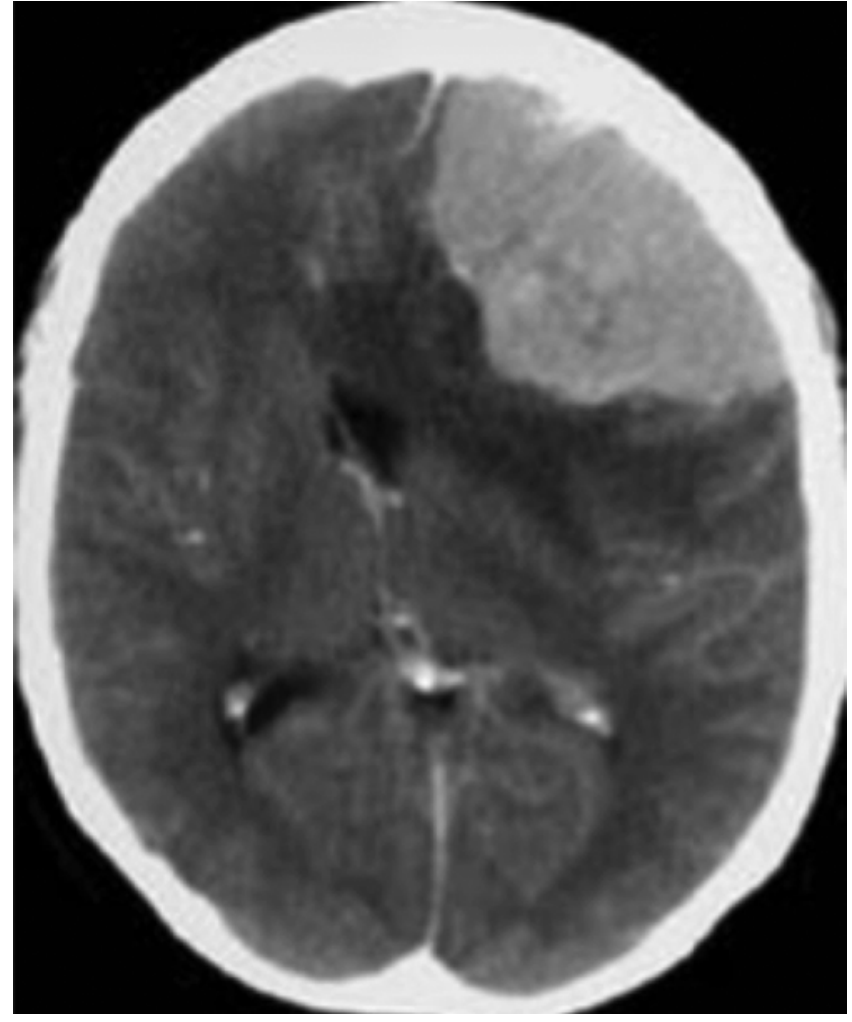

FIG. 1. Left frontal convexity meningioma. CT scan demonstrating a well-demarcated and homogeneously enhancing left frontal convexity meningioma. Peritumoral edema and mass effect are seen. Reproduced with permission from Dowd et al: Neurosurg Focus 15(1):E10, 2003

blood supply, complications, and new technical aspects of endovascular preoperative embolization of meningiomas.

\section{Epidemiology of Meningiomas}

Meningiomas are among the most common primary brain tumors, accounting for one-third of all central nervous system tumors. It is reported that there are 18,000 newly diagnosed cases each year with a prevalence of 138,000 cases in the United States alone. ${ }^{7}$ Studies estimate that more than $90 \%$ are WHO Grade I, $5 \%$ are Grade II, and $1 \%-3 \%$ are Grade III. ' The etiology is unknown; however, there is a correlation with prior radiation exposure and neurofibromatosis Type 2 . It has been found that $50 \%$ of meningiomas do not have merlin gene function on chromosome $22 .{ }^{39}$ Meningiomas demonstrate a higher female predominance with a female-to-male ratio of 3 or 2 to $1 .^{7}$ Olfactory groove lesions are the most common type of meningioma, followed by convexity, parasagittal, and sphenoid ridge meningiomas. ${ }^{23}$ Spinal meningiomas account for $10 \%$ of all cases.

\section{Endovascular Embolization and Pathophysiology}

Preoperative embolization is thought to reduce intraoperative complications by reducing operation time and blood loss. ${ }^{13,33}$ Embolization leads to devascularization of the lesion, which may induce necrosis and facilitate resection through tumor softening. Oka et al. demonstrated that patients with skull base meningiomas who underwent embolization of tumors smaller than $6 \mathrm{~cm}$ had significantly less blood loss..$^{27}$ In tumors larger than $6 \mathrm{~cm}$, there was no significant difference in blood loss between patients who had undergone embolization and those who had not, perhaps because larger meningiomas have collateral blood vessels in which embolization is unviable. ${ }^{27}$ It should be noted, however, that this paper only looked at preoperative embolization of skull base meningiomas and may not be applicable to all meningiomas. Skull base meningiomas are supplied by the internal carotid artery (ICA) and vertebrobasilar branches, which makes them challenging embolization targets. Regardless, the embolized group demonstrated a better clinical outcome than the nonembolized group..$^{27}$ Contrary to the study by Oka et al., a retrospective study by Quiñones-Hinojosa et al. that only analyzed giant meningiomas greater than or equal to $5 \mathrm{~cm}$ in varying intracranial locations demonstrated efficacy and facilitation of gross-total resection by embolization. ${ }^{29}$

Although highly efficacious, embolization does not always lead to complete obliteration of the tumor. Incomplete obliteration occurs due to multiple tumor feeders that share a blood supply with the brain parenchyma. ${ }^{38}$ Nevertheless, embolization helps facilitate surgical removal of a tumor by reducing bleeding volume and surgical time. Moreover, nimodipine, a dihydropyridine calcium channel blocker, administered before embolization may prevent vasospasm through vasodilation and may improve prognosis.

\section{Blood Supply and Location of Meningiomas}

Most meningiomas arise over the convexities (Fig. 1) or parasagittal areas, and $10 \%$ of meningiomas arise in the posterior fossa. ${ }^{16}$ Because meningiomas mainly arise from the dura, blood supply is usually from the meningeal arteries branching from the external carotid artery (ECA). ${ }^{16}$ The middle meningeal artery (MMA), the vessel that supplies the dura, is usually the main vessel that provides arterial blood to meningiomas. Meningiomas can recruit blood from nearby arteries or invade the dura. ${ }^{16}$ Table 1 summarizes the main cranial locations of meningiomas and their corresponding blood supply.

As listed in Table 1, the tentorium and clivus may receive arterial blood from the MMA and ICA. Embolization of the dural branches of the ICA is associated with risks, such as ischemic complications, and is thus not generally performed..$^{16}$ Olfactory groove meningiomas are supplied by the ethmoidal arteries as listed in Table 1. Embolization to this supply has the risk of affecting the ophthalmic artery and is therefore generally not performed. Instead, the surgical approach for these tumors is for the surgeon to coagulate the feeding vessels at the base before tumor resection. Similarly, embolization of the meningeal arteries from the vertebral artery or pial branches also carries risk and is not generally performed as often as embolization of ECA vessels. ${ }^{16}$

Embolization seems to be better for cranial vault meningiomas than for skull base meningiomas. ${ }^{33}$ Large cra- 
TABLE 1. Blood supply and location of meningiomas

\begin{tabular}{ll}
\hline \multicolumn{1}{c}{ Meningioma Location } & \multicolumn{1}{c}{ Blood Supply } \\
\hline Convexity & MMA \\
\hline Parasagittal & MMA \\
\hline Olfactory groove & Dural branches of the ICA; ethmoidal arteries; ophthalmic artery branches \\
\hline Tentorium/clivus & Cavernous ICA \& MMA; tentorial artery; arteries of Davidoff \& Schecter \\
\hline Posterior fossa (posteromedial) & Meningeal branches of the vertebral artery; posterior meningeal artery \\
\hline Posterior fossa (lateral) & Transmastoid branches of the occipital artery; ascending pharyngeal artery \\
\hline Falcine & Terminal arterial branches of the MMA; branches of the anterior falx artery \\
\hline Intraventricular & Choroidal arteries \\
\hline Sphenoid wing \& clinoidal & MMA \\
\hline
\end{tabular}

nial vault meningiomas are supplied by the meningeal, superficial temporal, and temporal arteries, which are accessible by surgical means. Skull base meningiomas are supplied by the ICA and branches of the vertebrobasilar system, which are difficult to catheterize. This is perhaps why Oka et al. demonstrated that there was no significant difference in blood loss between embolized and nonembolized patients with skull base tumors larger than $6 \mathrm{~cm} .{ }^{27}$ However, embolization has been shown to be most beneficial when used in convexity lesions, which can lead to significant blood loss due to their multidirectional blood supply. ${ }^{33}$ It is also useful when the blood supply to the tumor is located on the other side of the tumor in the surgeon's line of sight, which may preclude the need for exposure of the contralateral side during resections involving the falx or parasagittal regions..$^{33}$ Embolization has the advantage of excellent penetration of particulate or liquid materials into smaller meningeal artery branches down to $100 \mu \mathrm{m}$, resulting in tumor devascularization from the inside and minimization of hemorrhage. For some convexity meningiomas, the meningeal supply may be cauterized after the craniotomy before tumor removal, which can aid in reducing blood loss and devascularizing the tumor. This approach does help with reducing blood loss but it may not be as effective, as it does not occlude the deep penetrating small vessel blood supply. Simply occluding the meningeal supply can often lead to increased flow through other collateral vessels. In cases in which a meningioma is associated with a vascular lesion, such as an aneurysm or arteriovenous malformation, preoperative embolization may be vital to the success of tumor resection. ${ }^{33}$

\section{Embolization Materials Particulate Embolic Agents}

An effective embolic agent should be able to cause permanent distal vascular occlusions resulting in significant tumor necrosis. Table 2 reports the most commonly used materials in the embolization of meningiomas. A large percentage of surgeons use polyvinyl alcohol (PVA) particles, which is a solid embolic agent. ${ }^{10,33}$ PVA particles are a spongy material that is created when PVA is mixed with foaming substances and hardened with formaldehyde. ${ }^{24}$ PVA particles expand in an aqueous solution due to their spongelike quality; moreover, they produce an inflammatory response that aids in thrombosis and occlusion.

\section{Microspheres}

Microspheres are another competing material, which, when suspended in contrast material, are flexible and compressible. These characteristics make microspheres easy to use without causing catheter blockage..$^{35}$ According to Bendszus et al., trisacryl gelatin microspheres are associated with lower operative blood loss than PVA [particles]. ${ }^{1}$ However, Sluzewski et al. demonstrated that the use of $400-\mu \mathrm{m}$ calibrated microspheres in the embolization of meningiomas had a comparable complication rate to using small PVA particles of $45-150 \mu \mathrm{m} .{ }^{35}$ It was also demonstrated that the use of 400- $\mu \mathrm{m}$ microspheres had a complication rate comparable to that of larger PVA particles of 150 to $250 \mu \mathrm{m}$. The general consensus is that smaller embolization particles carry an increased risk for intratumoral hemorrhage but are also associated with a higher rate of postembolization tumor necrosis. ${ }^{35,37}$

\section{Liquid Embolic Agents}

Liquid agents have been shown to have more operational and efficacious advantages over other particle agents. Studies have also suggested that particulate embolization has a higher risk of hemorrhage than liquid embolization. ${ }^{38}$ Wang et al. reported that although embolization was successful in all patients and resulted in 50\%-100\% obliteration of the tumor mass on angiography, 2 of the 7 patients who were treated with particle embolization developed bleeding related to the embolization procedure. ${ }^{38}$

TABLE 2. Various materials used for embolization of meningiomas by type

\begin{tabular}{lll}
\hline Particulate Material & \multicolumn{1}{c}{ Liquid Material } & Microspheres \\
\hline PVA & Estrogen & $\begin{array}{c}\text { Trisacryl gelatin } \\
\text { microspheres }\end{array}$ \\
\hline $\begin{array}{l}\text { Porous cellulose } \\
\text { beads }\end{array}$ & Phenytoin & \\
\hline Hydroxyapatite & Onyx-18 & \\
\hline Estrogen+PVA & Lipiodol & \\
\hline Gelfoam & Glubran \\
\hline GDCs & NBCA \\
\hline Platinum microcoils & Dextrose/Hypaque & \\
\hline
\end{tabular}

$\mathrm{GDC}=$ Guglielmi Detachable Coil. 
None of the 5 patients treated with liquid embolic agents developed bleeding related to the procedure. Although a small sample size, this study demonstrated that particle embolization might carry a higher risk of hemorrhage than liquid agents. The mechanism is unclear; however, it is purported that tumor necrosis due to deep penetration in small venules via arteriovenous fistulas obstructs venous outflow. Liquid agents maximize devascularization because both the main and distal vessels are occluded simultaneously, which reduces the risk of bleeding from the collateral vessels. The use of liquid embolic material can also reduce procedure time if there is a single tumor feeder. ${ }^{38}$ Shortening the procedure time is important for patient safety. Using liquid embolic material also decreases the amount of contrast medium required for suspension, which is beneficial in neonatal patients. ${ }^{38}$ One potential shortcoming of liquid agents is the insufficient permeation into the meningioma when a microcatheter is in the wedge position. ${ }^{38}$

Kominami et al. also demonstrated that a liquid agent, $\mathrm{N}$-butyl cyanoacrylate (NBCA), has a lower risk of hemorrhage and ischemic complications compared with particle agents such as PVA. ${ }^{20}$ Kominami et al. and Borg et al. corroborated that NBCA can be administered with a broader range of microcatheters and thus it confers superior distal navigation compared with particle agents. ${ }^{3,20}$ NBCA can enter meningioma vessels simultaneously, which helps to prevent intratumoral bleeding that is a common complication of solid embolic materials. Furthermore, NBCA can be delivered with a lower injection pressure than solid agents, which also helps to prevent hemorrhage..$^{20}$ NBCA, when added with Lipiodol, is radiopaque and can aid in detecting the movement of embolic material into dangerous anastomoses. One potential limitation is that when the microcatheter is far from the meningioma, NBCA may occlude the vessel proximally with a risk of glue reflux; ${ }^{20}$ however, this occlusion is still beneficial and carries a lower risk of hemorrhage than distal PVA embolization. Other materials such as PVA particles can be considered if the microcatheter tip is not close enough to the meningioma.

Onyx (ev3, Inc.), an ethylene vinyl alcohol copolymer, is a newer liquid that has gained popularity for its successful use with arteriovenous malformations and fistulas. ${ }^{10}$ The slower precipitation of Onyx gives it some advantages over other liquid agents such as NBCA because it can permeate deeper within the tumor vessels. ${ }^{10}$ Furthermore, Onyx administration may be intermittently stopped for early detection of intracranial anastomoses and any evidence of nontargeted embolization. ${ }^{10}$ Although particulate agents are cheaper options, they have some disadvantages compared with Onyx. Particulate embolic agents are radiolucent and need contrast solution, cannot be used in direct puncture, and can dissolve over time, which may allow for revascularization. ${ }^{10}$

\section{Imaging Techniques and Their Use for Preoperative Embolization}

There have been many improvements in imaging methods that have aided embolization therapeutics. MRI and CT are imaging tools that have high anatomical resolu- tion. ${ }^{32}$ Meningiomas have a recognizable appearance on MRI and CT. These imaging modalities can suggest histological tumor diagnosis, but are not accurate enough to detect the grade. Angiography can be useful during embolization of meningiomas and is useful in elucidating the vessels that feed the lesion (Fig. 2). MR images, CT scans, and cerebral angiography can all be used to aid in diagnosing, evaluating, and treating meningiomas: MRI for delineating anatomical relationships, CT for screening/ evaluating anatomy, and angiography for analyzing vessels for embolization. ${ }^{11,19}$ Understanding how embolization is affected by various imaging modalities is critical for meningioma therapeutics, can aid with assessing the efficacy of embolization, and can help deliver embolic agents.

\section{Angiography}

Angiography can be used to assess the viability of preoperative embolization (Fig. 2).9,11,36 Digital subtraction angiography can be used to analyze meningioma vascularity and its relationship with surrounding vessels. Angiography can also determine the site of attachment, patency of sinuses, collateral circulation, and arterial encasement. ${ }^{24}$ Understanding how embolization may affect imaging modalities is critical for meningioma therapeutics. Although one may see MRI changes after embolization, such as a decrease in enhancement and reduced diffusion of the devascularized portion of the meningioma, there can be complications such as hemorrhage and necrosis that can obfuscate MRI findings. ${ }^{32}$ A meningioma generally appears as a "spokewheel" pattern of intratumoral arteries around a main vessel. ${ }^{16}$ Embolization is reserved for meningiomas with high vascularity on angiography findings. ${ }^{16}$

Although safe, angiography is not without danger. Heiserman et al. reported a $1 \%$ incidence of neurological deficits related to angiography..$^{14}$ However, a meta-analysis of cerebral angiography found only a $0.07 \%$ rate of neurological deficit and a $0.6 \%$ rate of nonneurological complications. ${ }^{8}$ Mani and Eisenberg further demonstrated that the complication rate was lower for patients with tumors than for patients with subarachnoid hemorrhage or cerebrovascular occlusive disease. ${ }^{22}$

\section{MRI}

Although MRI can be used to analyze the effects of

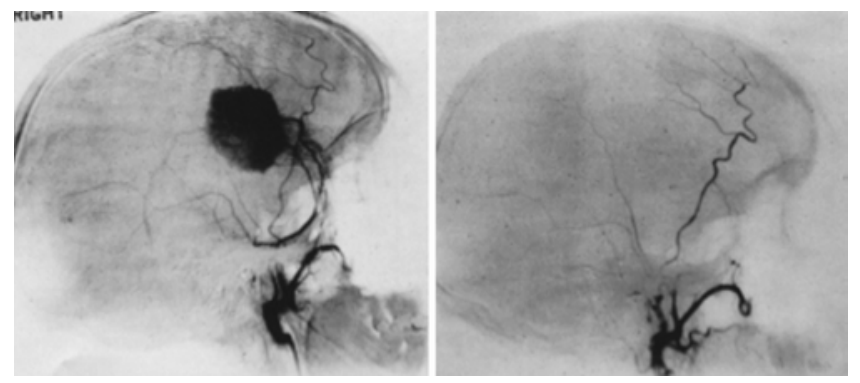

FIG. 2. Cerebral pre- and postembolization ECA angiograms. Left: Angiogram depicting a meningioma with many feeding vessels. Right: Repeat angiogram after embolization depicting $90 \%$ obliteration of vasculature. Reproduced with permission from Teasdale et al: J Neurosurg 60:506-511, 1984. 
embolization, it may be challenging to assess efficacy due to contrast leakage, heterogeneous meningioma composition, and different grades of recanalization. ${ }^{26}$ MRI may underestimate the effect of embolization on the tumor. ${ }^{11}$ Nishiguchi et al. stated that evaluations using dynamic susceptibility perfusion-weighted imaging, diffusion-weighted imaging, and MR spectroscopy lack spatial resolution. Furthermore, embolization-related tumor changes cannot be seen on images based on the amount of cerebral blood volume or cerebrospinal fluid, which could increase due to compensatory vasodilatation. ${ }^{26} \mathrm{~A}$ new MRI sequence that demonstrates tumor composition and degree of ischemia after embolization is necessary. Recent analysis has demonstrated that T2-weighted MRI enables the examination of tumor hypoxia related to blood flow changes. ${ }^{26}$ Areas of decreased T2 signal are correlated with hypoxia; Nishiguchi et al. demonstrated a decrease in T2 signal after embolization in their meningioma model.

Saloner et al. reported that MR perfusion using intraarterial injections is a new, potentially useful technique in evaluating meningioma perfusion. ${ }^{32}$ In traditional MR perfusion with intravenous injections, the contrast is transported throughout the vasculature in the body; therefore, imaging of an area of interest is nonselective and would reflect perfusion from all arterial supplies. Intraarterial MR perfusion can help analyze the end organ and can be performed during catheterization for embolization. Assessing the perfusion status is crucial in determining whether the embolization is successful and can help to guide therapeutics.

Moreover, gradient recalled echo MRI is sensitive to the oxygenation state of meningioma lesions and thus blood perfusion status. A potentially useful imaging modality for identifying biomarkers is noncontrast-enhanced susceptibility-weighted principles of echo shifting with a train of observations (SW-PRESTO). This imaging technique can analyze the amount of necrosis of the meningioma by enhancing gradient recalled echo image contrast based on the differences between deoxygenated red blood cells and background tissue. ${ }^{26}$ Although more study is needed, this 3D susceptibility-weighted imaging method is a new potential imaging modality that can aid in meningioma therapeutics by analyzing various degrees of ischemia in embolized meningiomas.

\section{Interval Between Embolization and Resection}

There is much controversy regarding the interval between the embolization procedure and subsequent resection surgery. ${ }^{17}$ Studies have reported broad ranging data that seem to corroborate 2 opposite conclusions. Currently, the average time until surgery after embolization ranges from 1.9 to 6.3 days. ${ }^{33,34}$ The range for surgery after embolization varies between 0 and 30 days.

$\mathrm{Ng}$ et al. described a wide range of histological changes in 25 patients who underwent embolization with PVA particles (150-300 $\mu \mathrm{m})$ at different intervals. The authors concluded that changing the interval between embolization and resection yielded no prognostic significance. ${ }^{25}$ Others have also reported no difference in tumor resection when the interval varied from several hours to 2.5 months. ${ }^{30}$ On the other hand, Wang et al. reported that waiting too long may increase the risk of tumor hemorrhage and may increase the chance that collaterals to the occluded area will be recreated. ${ }^{38}$ Earlier resection can also minimize other risks such as mass effect from edema or obstructive hydrocephalus. ${ }^{38}$ While there are no complications associated with a shorter interval, operating too soon may not allow for adequate occlusion of the blood supply, which may lead to longer operative time, smaller areas of necrosis and tumor softening, larger blood transfused volumes, and longer length of hospital stay. ${ }^{24}$

In contrast, Nania et al. analyzed 28 meningioma cases, and their experience dictates that patients should undergo surgery at least 7 days after embolization. ${ }^{24} \mathrm{~A}$ shorter interval between embolization and resection was correlated with a higher transfused blood volume and longer surgical time. Larger areas of necrosis were more prevalent in patients with a longer interval between embolization and resection. ${ }^{24}$ Some studies have also demonstrated that delaying surgery after embolization leads to less bleeding. ${ }^{33}$ Such benefits should be weighed against the risk associated with embolization in the days immediately after the procedure. There is an associated delayed reaction of embolization such as tumor mass effect that can lead to herniation or obstructive hydrocephalus. ${ }^{38}$ Nevertheless, Nania et al. purported that the ideal interval of at least 7 days maximizes tumor necrosis while minimizing blood loss and morbidity from other factors. ${ }^{24}$ Although there are no reported data analyzing various subtypes of meningiomas and preferred intervals, smaller meningiomas without significant edema may be more amenable to longer intervals between embolization and surgery. Perhaps the stark discrepancy in literature is a result of advancements in therapeutics and embolization over time.

\section{Complications}

Presurgical embolization is associated with a complication rate ranging from $0 \%$ to $9 \%$ (Table 3 ) and is often due to cranial nerve damage rather than to hemorrhage. . $^{3,518,28,33}$ Table 3 summarizes the complications related to embolization treatment of meningiomas from various cohorts. The overall success rate for embolization ranges from $91 \%$ to $100 \%$, which is also summarized in Table 3 . The less prevalent, albeit severe, complications include unintended ischemia, mass effect, hydrocephalus, edema, seizures, hemiparesis, glaucoma, syndrome of inappropriate antidiuretic hormone, disseminated intravascular coagulation, and infection., $2,12,15,28,31,33$ Intratumoral hemorrhage may have horrific consequences. Extravasation of blood into the tumor causes edema with mass effect that could lead to herniation. ${ }^{35}$ The potential for intraoperative bleeding is much worse for younger patients. ${ }^{38}$

Although the pathophysiology of hemorrhage is not fully understood, there are several hypothesized mechanisms: 1) collaterals receive increased flow leading to rupture; 2) penetration of embolic agents into the draining veins may impede outflow; ${ }^{35} 3$ ) continuous injection of the embolic agent increases pressure in feeding arteries, leading to rupture; 4) strenuous manipulation of the catheter causes damage to vessels; and 5) forceful test injection. ${ }^{38}$ 
TABLE 3. Review of studies for embolization of meningiomas*

\begin{tabular}{|c|c|c|c|c|c|c|c|}
\hline $\begin{array}{l}\text { Authors \& } \\
\quad \text { Year }\end{array}$ & $\begin{array}{l}\text { Pathology } \\
\text { Treated }\end{array}$ & $\begin{array}{l}\text { Cohort } \\
\text { Size }\end{array}$ & Complications & $\begin{array}{l}\text { Complication } \\
\text { Rate }\end{array}$ & Success Rate & Notes & Embolic Agent \\
\hline $\begin{array}{l}\text { Borg et al., } \\
2013\end{array}$ & Meningioma & 117 & $\begin{array}{l}\text { Mortality, postsurgical } \\
\text { hemorrhage }(n=1) \text {; } \\
\text { tumor hemorrhage } \\
(n=2) ; 6 \text { th nerve } \\
\text { palsy }(n=1) ; \text { scalp } \\
\text { necrosis }(n=1)\end{array}$ & $4.3 \%$ & $95.3 \%$ & $\begin{array}{l}10 \text { cases of the original } \\
117 \text { were abandoned. }\end{array}$ & Glue/particle \\
\hline $\begin{array}{l}\text { Probst et al., } \\
1999\end{array}$ & Meningioma & 80 & $\begin{array}{l}\text { Incomplete paresis } \\
\text { of facial nerve } \\
\text { (transient) }(n=1) ; \\
\text { hypesthesia of the } \\
\text { sensory area of the } \\
\text { 3rd trigeminal nerve } \\
(n=1)\end{array}$ & $2.5 \%$ & $97.5 \%$ & $\begin{array}{l}\text { Embolization was per- } \\
\text { formed w/ a fibrin glue } \\
\text { preparation. }\end{array}$ & Fibrin glue \\
\hline $\begin{array}{l}\text { Carli et al., } \\
2010\end{array}$ & Meningioma & 198 & $\begin{array}{l}\text { Hemorrhagic }(n=10) \text {, } \\
\text { ischemic }(n=1)\end{array}$ & $5.6 \%$ & $94.4 \%$ & $\begin{array}{l}2 \text { patients died, \& } 5 \text { had } \\
\text { dependency. }\end{array}$ & Particle (PVA) \\
\hline $\begin{array}{l}\text { Bendszus et } \\
\text { al., } 2005\end{array}$ & Meningioma & 185 & $\begin{array}{l}\text { Ischemic event } w / \text { neu- } \\
\text { rological deficit }(n= \\
6) ; \text { hemorrhage }(n= \\
6 ; 1 \text { was lethal) }\end{array}$ & $6.5 \%$ & $93.5 \%$ & $\begin{array}{l}\text { From the ischemic } \\
\text { complications, } 2 \text { had } \\
\text { amaurosis \& } 4 \text { had } \\
\text { hemiparesis. }\end{array}$ & $\begin{array}{l}\text { Spherical par- } \\
\quad \text { ticles }\end{array}$ \\
\hline $\begin{array}{l}\text { Rosen et al., } \\
2002\end{array}$ & $\begin{array}{l}\text { Cranial base } \\
\text { menin- } \\
\text { gioma }\end{array}$ & 167 & $\begin{array}{l}\text { Transient worsening of } \\
\text { neurological exam } \\
(n=21) \text {; permanent } \\
\text { neurological deficits/ } \\
\text { morbidity }(n=15)\end{array}$ & $9 \%$ & $91 \%$ & $\begin{array}{l}20 \text { patients were not } \\
\text { embolized due to } \\
\text { neurological deficits/ } \\
\text { lack of a suitable ves- } \\
\text { sel for procedure. } 4 \text { of } \\
\text { the patients w/ severe } \\
\text { complications had } \\
\text { a decline in cranial } \\
\text { nerve function. }\end{array}$ & Particle (PVA) \\
\hline $\begin{array}{l}\text { Gruber et } \\
\text { al., } 2000^{12}\end{array}$ & $\begin{array}{l}\text { Skull base } \\
\text { menin- } \\
\text { gioma }\end{array}$ & 66 & $\begin{array}{l}\text { Permanent disability ( } \\
\quad=2) ; \text { death }(n=1)\end{array}$ & $4.5 \%$ & $95.5 \%$ & $\begin{array}{l}\text { Complications were } \\
\text { related to throm- } \\
\text { boembolic events } \\
\text { rather than to catheter } \\
\text { embolization itself. }\end{array}$ & $\begin{array}{l}\text { PVA particles or } \\
\text { cyanoacry- } \\
\text { lates (NBCA) }\end{array}$ \\
\hline $\begin{array}{l}\text { Chun et al., } \\
2002\end{array}$ & Meningioma & 50 & $\begin{array}{l}\text { Uncomplicated groin } \\
\text { hematoma from } \\
\text { angiography }(n=1)\end{array}$ & $2 \%$ & $98 \%$ & & $\begin{array}{l}\text { PVA particles w/ } \\
\text { or w/o GDCs }\end{array}$ \\
\hline $\begin{array}{l}\text { Kai et al., } \\
2002\end{array}$ & Meningioma & 42 & $\begin{array}{l}\text { Intratumoral hemor- } \\
\quad \text { rhage }(n=1) \text {; hear- } \\
\text { ing loss }(n=1)\end{array}$ & $4.8 \%$ & $95.2 \%$ & $\begin{array}{l}\text { There were no transient } \\
\text { postembolization } \\
\text { complications. }\end{array}$ & $\begin{array}{l}\text { Particles made } \\
\text { of cellulose } \\
\text { porous beads } \\
\text { or nonabsorb- } \\
\text { able particles }\end{array}$ \\
\hline $\begin{array}{l}\text { Sluzewski et } \\
\text { al., } 2013\end{array}$ & Meningioma & 55 & $\begin{array}{l}\text { No hemorrhagic or } \\
\text { ischemic complica- } \\
\text { tions }(n=0)\end{array}$ & $0 \%$ & $100 \%$ & $\begin{array}{l}\text { Microspheres were used } \\
\text { instead of PVA. }\end{array}$ & Microspheres \\
\hline $\begin{array}{l}\text { Gruber et al., } \\
2000^{13}\end{array}$ & Meningioma & 63 & $\begin{array}{l}\text { Complications due } \\
\text { to using outdated } \\
\text { techniques }(n=3)\end{array}$ & $4.8 \%$ & $\begin{array}{l}\text { Total or subtotal } \\
\text { angiographic } \\
\text { devascularization } \\
\text { of tumor } 60.3 \% \text { ( } n \\
\text { = 38); partial tu- } \\
\text { mor embolization } \\
39.7 \%(n=25)\end{array}$ & & \\
\hline $\begin{array}{l}\text { Hishikawa et } \\
\text { al., } 2014\end{array}$ & Meningioma & 898 & $(n=9)$ & $1.0 \%$ & $98.9 \%$ & & $\begin{array}{l}\text { Liquid, particle, } \\
\text { \& coil }\end{array}$ \\
\hline
\end{tabular}

* The success rate is defined as percentage of successful cases without complications, transient or not. Relevant cohorts with 50 or more patients were included in this table. 
Identifying the bleeding accurately and providing the correct care are critical for the outcome.

\section{Future Directions of Therapeutics (Direct Puncture Embolization)}

Despite some of the reported benefits of transarterial embolization, a new approach has allowed for in situ administration. This new approach is known as intraoperative intratumoral direct needle puncture, whereby neurosurgeons identify parent vessels and reduce blood loss with a more targeted approach. This may prove to be efficacious and may offer an alternative to current embolization methods..$^{10,33}$ Embolization can be difficult using traditional approaches due to the tortuosity of the vessels and the varying angles at which they sprout. Direct needle puncture has proven to be efficacious with a mean tumor devascularization of $87 \% .^{10}$ Onyx serves as a good material for embolization by direct needle puncture because of its slower precipitation. ${ }^{10}$ Elhammady et al. reported that Onyx, via direct needle puncture, demonstrated effective intravascular penetration and was located completely inside the vascular spaces of the tumors on histological analysis. ${ }^{10}$ Direct puncture reduces the chance of affecting nontarget vessels. Transarterial embolization can lead to inadequate occlusion, which then necessitates direct catheterization of vessels and thus increases overall procedure time. ${ }^{10}$ Despite the benefits, direct needle puncture may increase the risk of embolization of venous vessels. ${ }^{10}$ More research is needed before conclusions can be extrapolated.

\section{Conclusions}

Surgical approaches that devascularize meningiomas and lead to tumor softening are becoming increasingly important in therapeutic techniques for treating these tumors. Although somewhat controversial, embolization has been shown to be efficacious in meningioma treatment and resection. Embolization is most beneficial when used on dangerous tumors that could lead to significant blood loss, such as giant convexity lesions with multidirectional blood supply, or when the blood supply to the tumor is located deep in the surgeon's line of sight. It has been demonstrated that liquid embolic materials are preferable to particle agents because particle embolization carries a higher risk of hemorrhage. Liquid agents maximize the effect of devascularization because of deeper penetration into the trunk and distal tumor vessels. Unfortunately, there is still a lack of consensus on whether the interval between embolization and resection affects prognosis, and more data are needed. The 3 main imaging techniques, MRI, CT, and angiography, can all be used in a complementary fashion to aid in analyzing and treating meningiomas; however, angiography is currently the most useful tool for assessing tumor vascularity and usefulness of preoperative embolization. Intraarterial MR perfusion imaging and SW-PRESTO imaging biomarkers can relay information about perfusion status and degrees of ischemia in embolized meningiomas and could be very useful in the realm of therapeutics with embolic material delivery. Direct puncture is yet another therapeutic technique that would allow for more accurate embolization and less blood loss during resection.

\section{Acknowledgment}

We thank Cheryl J. Christensen for help with preparation of the manuscript.

\section{References}

1. Bendszus M, Klein R, Burger R, Warmuth-Metz M, Hofmann E, Solymosi L: Efficacy of trisacryl gelatin microspheres versus polyvinyl alcohol particles in the preoperative embolization of meningiomas. AJNR Am J Neuroradiol 21:255-261, 2000

2. Bendszus M, Monoranu CM, Schütz A, Nölte I, Vince GH, Solymosi L: Neurologic complications after particle embolization of intracranial meningiomas. AJNR Am J Neuroradiol 26:1413-1419, 2005

3. Borg A, Ekanayake J, Mair R, Smedley T, Brew S, Kitchen $\mathrm{N}$, et al: Preoperative particle and glue embolization of meningiomas: indications, results and lessons learned from 117 consecutive patients. Neurosurgery 73 (2 Suppl Operative):ons244-ons252, 2013

4. Boulos PT, Dumont AS, Mandell JW, Jane JA Sr: Meningiomas of the orbit: contemporary considerations. Neurosurg Focus 10(5):E5, 2001

5. Carli DF, Sluzewski M, Beute GN, van Rooij WJ: Complications of particle embolization of meningiomas: frequency, risk factors, and outcome. AJNR Am J Neuroradiol 31:152154,2010

6. Chun JY, McDermott MW, Lamborn KR, Wilson CB, Higashida R, Berger MS: Delayed surgical resection reduces intraoperative blood loss for embolized meningiomas. Neurosurgery 50:1231-1237, 2002

7. Claus EB, Bondy ML, Schildkraut JM, Wiemels JL, Wrensch M, Black PM: Epidemiology of intracranial meningioma. Neurosurgery 57:1088-1095, 2005

8. Cloft HJ, Joseph GJ, Dion JE: Risk of cerebral angiography in patients with subarachnoid hemorrhage, cerebral aneurysm, and arteriovenous malformation: a meta-analysis. Stroke 30:317-320, 1999

9. Dowd CF, Halbach VV, Higashida RT: Meningiomas: the role of preoperative angiography and embolization. Neurosurg Focus 15(1):E10, 2003

10. Elhammady MS, Peterson EC, Johnson JN, Aziz-Sultan MA: Preoperative onyx embolization of vascular head and neck tumors by direct puncture. World Neurosurg 77:725-730, 2012

11. Engelhard HH: Progress in the diagnosis and treatment of patients with meningiomas. Part I: diagnostic imaging, preoperative embolization. Surg Neurol 55:89-101, 2001

12. Gruber A, Bavinzski G, Killer M, Richling B: Preoperative embolization of hypervascular skull base tumors. Minim Invasive Neurosurg 43:62-71, 2000

13. Gruber A, Killer M, Mazal P, Bavinzski G, Richling B: Preoperative embolization of intracranial meningiomas: a 17-years single center experience. Minim Invasive Neurosurg 43:18-29, 2000

14. Heiserman JE, Dean BL, Hodak JA, Flom RA, Bird CR, Drayer BP, et al: Neurologic complications of cerebral angiography. AJNR Am J Neuroradiol 15:1401-1411, 1994

15. Hishikawa T, Sugiu K, Hiramatsu M, Haruma J, Tokunaga K, Date I, et al: Nationwide survey of the nature and risk factors of complications in embolization of meningiomas and other intracranial tumors: Japanese Registry of NeuroEndovascular Therapy 2 (JR-NET2). Neuroradiology 56:139-144, 2014

16. Hurst RW, Rosenwasser RH: Interventional Neuroradiology. New York: Informa Healthcare, 2008

17. Kai Y, Hamada J, Morioka M, Yano S, Todaka T, Ushio $\mathrm{Y}$ : Appropriate interval between embolization and surgery in patients with meningioma. AJNR Am J Neuroradiol 23:139-142, 2002 
18. Kallmes DF, Evans AJ, Kaptain GJ, Mathis JM, Jensen ME, Jane JA, et al: Hemorrhagic complications in embolization of a meningioma: case report and review of the literature. Neuroradiology 39:877-880, 1997

19. Kim PE, Singh M: Functional magnetic resonance imaging for brain mapping in neurosurgery. Neurosurg Focus 15(1):E1, 2003

20. Kominami S, Watanabe A, Suzuki M, Mizunari T, Kobayashi $\mathrm{S}$, Teramoto A: Preoperative embolization of meningiomas with N-butyl cyanoacrylate. Interv Neuroradiol 18:133-139, 2012

21. Manelfe C, Guiraud B, David J, Eymeri JC, Tremoulet M, Espagno J, et al: [Embolization by catheterization of intracranial meningiomas.] Rev Neurol (Paris) 128:339-351, 1973 (Fr)

22. Mani RL, Eisenberg RL: Complications of catheter cerebral arteriography: analysis of 5,000 procedures. II. Relation of complication rates to clinical and arteriographic diagnoses. AJR Am J Roentgenol 131:867-869, 1978

23. Mezue WC, Ohaegbulam SC, Ndubuisi CC, Chikani MC, Achebe DS: Intracranial meningiomas managed at Memfys hospital for neurosurgery in Enugu, Nigeria. J Neurosci Rural Pract 3:320-323, 2012

24. Nania A, Granata F, Vinci S, Pitrone A, Barresi V, Morabito $\mathrm{R}$, et al: Necrosis score, surgical time, and transfused blood volume in patients treated with preoperative embolization of intracranial meningiomas. Analysis of a single-centre experience and a review of literature. Clin Neuroradiol 24:29-36, 2014

25. Ng HK, Poon WS, Goh K, Chan MS: Histopathology of postembolized meningiomas. Am J Surg Pathol 20:1224-1230, 1996

26. Nishiguchi T, Iwakiri T, Hayasaki K, Ohsawa M, Yoneda T, Mitsuhashi Y, et al: Post-embolisation susceptibility changes in giant meningiomas: multiparametric histogram analysis using non-contrast-enhanced susceptibility-weighted PRESTO, diffusion-weighted and perfusion-weighted imaging. Eur Radiol 23:551-561, 2013

27. Oka H, Kurata A, Kawano N, Saegusa H, Kobayashi I, Ohmomo T, et al: Preoperative superselective embolization of skull-base meningiomas: indications and limitations. J Neurooncol 40:67-71, 1998

28. Probst EN, Grzyska U, Westphal M, Zeumer H: Preoperative embolization of intracranial meningiomas with a fibrin glue preparation. AJNR Am J Neuroradiol 20:1695-1702, 1999

29. Quiñones-Hinojosa A, Kaprealian T, Chaichana KL, Sanai N, Parsa AT, Berger MS, et al: Pre-operative factors affecting resectability of giant intracranial meningiomas. Can J Neurol Sci 36:623-630, 2009

30. Richter HP, Schachenmayr W: Preoperative embolization of intracranial meningiomas. Neurosurgery 13:261-268, 1983
31. Rosen CL, Ammerman JM, Sekhar LN, Bank WO: Outcome analysis of preoperative embolization in cranial base surgery. Acta Neurochir (Wien) 144:1157-1164, 2002

32. Saloner D, Uzelac A, Hetts S, Martin A, Dillon W: Modern meningioma imaging techniques. J Neurooncol 99:333-340, 2010

33. Shah AH, Patel N, Raper DM, Bregy A, Ashour R, Elhammady MS, et al: The role of preoperative embolization for intracranial meningiomas. J Neurosurg 119:364-372, 2013

34. Singla A, Deshaies EM, Melnyk V, Toshkezi G, Swarnkar A, Choi H, et al: Controversies in the role of preoperative embolization in meningioma management. Neurosurg Focus 35(6):E17, 2013

35. Sluzewski M, van Rooij WJ, Lohle PN, Beute GN, Peluso JP: Embolization of meningiomas: comparison of safety between calibrated microspheres and polyvinyl-alcohol particles as embolic agents. AJNR Am J Neuroradiol 34:727-729, 2013

36. Teasdale E, Patterson J, McLellan D, Macpherson P: Subselective preoperative embolization for meningiomas. A radiological and pathological assessment. J Neurosurg 60:506-511, 1984

37. Wakhloo AK, Juengling FD, Van Velthoven V, Schumacher M, Hennig J, Schwechheimer K: Extended preoperative polyvinyl alcohol microembolization of intracranial meningiomas: assessment of two embolization techniques. AJNR Am J Neuroradiol 14:571-582, 1993

38. Wang HH, Luo CB, Guo WY, Wu HM, Lirng JF, Wong TT, et al: Preoperative embolization of hypervascular pediatric brain tumors: evaluation of technical safety and outcome. Childs Nerv Syst 29:2043-2049, 2013

39. Yang C, Asthagiri AR, Iyer RR, Lu J, Xu DS, Ksendzovsky A, et al: Missense mutations in the NF2 gene result in the quantitative loss of merlin protein and minimally affect protein intrinsic function. Proc Natl Acad Sci U S A 108:49804985, 2011

\section{Author Contributions}

Conception and design: Shah, Choudhri. Acquisition of data: Shah. Analysis and interpretation of data: Shah. Drafting the article: Shah. Critically revising the article: all authors. Reviewed submitted version of manuscript: all authors. Approved the final version of the manuscript on behalf of all authors: Li. Administrative/technical/material support: all authors. Study supervision: Li, Choudhri, Jung.

\section{Correspondence}

Gordon Li, Department of Neurosurgery, Stanford University, 1201 Welch Rd. P309, Stanford, CA 94305. email: gordonli@ stanford.edu. 